\title{
Mortality in an ICU of a tertiary hospital
}

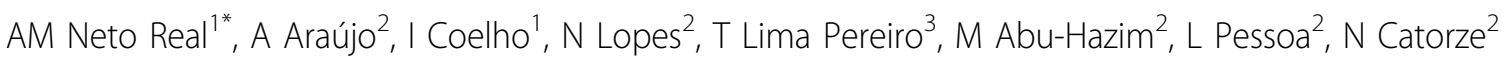 \\ From ESICM LIVES 2015 \\ Berlin, Germany. 3-7 October 2015
}

\section{Introduction}

Evaluation of mortality showed that in many ICU mortality in critically ill patients may range from $6.4 \%$ to $40 \%$ despite best care provided [1,2]. This variability is considerable and persistent even after adjustment based on the characteristics of the patient on admission [3-8].

\section{Objectives and Methods}

A retrospective observational study that aims to assess, analyze and characterize mortality in ICU -ABT, in 2014.

\section{Results}

In this period, there were 608 admissions. The severity indices measured reached 48.5 points for SAPS II, and APACHE II 25.6 corresponding to a mortality rate of $43.8 \%$ and $56.9 \%$, respectively. There were in total 170 deaths $(27.9 \%)$. Of these, the majority were male (104 vs $66 ; 61 \%$ vs $39 \%$ ) and the average age was 75.4 years and ranged between 37-97 years. The most prevalent age range was between $70-79$ years $(36 \%, \mathrm{n}=61)$. The average length of stay was 3.89 vs 2.99 days in patients who died. $54 \%(n=92)$ of the deceased patients remained less than 24 hours in the ICU. Regarding the type of patient admitted, $82 \%$ presented a medical diagnosis $(\mathrm{n}=139)$, 9.5\% $(\mathrm{n}=16)$ surgical-urgent and $8.5 \%(\mathrm{n}=15)$ surgicalelective diagnosis. The most prevalent primary diagnosis was septic shock which included 55 patients $(32.4 \%)$ and cardio-respiratory arrest post-status in $13.5 \%(n=23)$. The severity indices (APACHE II, and SAPS II) of the deceased patients reached 64 and 33 (75\% and $78.6 \%)$ respectively. in the ICU, reflecting a late referral to the unit. The analysis of the severity index points to an estimated mortality higher than the observed, exposing a high quality of care provided.

\section{Authors' details \\ ${ }^{1}$ Internal Medicine Department, Abrantes, Portugal. ${ }^{2} \mathrm{CHMT}$, ICU Department, Abrantes, Portugal. ${ }^{3} \mathrm{CHMT}$, ICU Department, Intensive Care Unit, Abrantes,} Portugal.

Published: 1 October 2015

\section{References}

1. Azoulay, et al: Determinants of postintensive care unit mortality: a prospective multicenter study. Crit Care Med 2003.

2. Knaus WA, et al: Variations in mortality and length of stay in intensive care units. Ann Intern Med 1993, May.

3. Gunning K, Rowan K: $A B C$ of intensive care: outcome data and scoring systems. BMJ 1999, Jul 24.

4. Gunning $\mathrm{K}: \mathrm{ABC}$ of intensive care: outcome data and scoring systems. BMJ 1999, Jul 24

5. Shortell SM, et al: Continuously improving patient care: practical lessons and an assessment tool from the National ICU Study. QRB Qual Rev Bull 1992, May.

6. Kuzniewicz MW, Vasilevskis EE, Lane $\mathrm{R}$, et al: Variation in ICU risk-adjusted mortality: impact of methods of assessment and potential confounders. Chest 2008, Jun.

7. Rothen $\mathrm{HU}$, et al: Variability in outcome and resource use in intensive care units. Intensive Care Med 2007, Aug.

8. Render $\mathrm{ML}$, et al: Variation in outcomes in Veterans Affairs intensive care units with a computerized severity measure. Crit Care Med 2005, May.

doi:10.1186/2197-425X-3-S1-A338

Cite this article as: Neto Real et al:: Mortality in an ICU of a tertiary hospital. Intensive Care Medicine Experimental 2015 3(Suppl 1):A338.

\section{Conclusions}

The data presented are consistent with the literature. Septic shock, most prevalent entity among the deceased, presented a mortality of up to $50 \%$, so its strong representation is not surprising. It is to emphasize the fact that more than $50 \%$ of the deceased stayed less than 24 hours

${ }^{1}$ Internal Medicine Department, Abrantes, Portugal

Full list of author information is available at the end of the article

(C) 2015 Neto Real et al.; This is an Open Access article distributed under the terms of the Creative Commons Attribution License (http://creativecommons.org/licenses/by/4.0), which permits unrestricted use, distribution, and reproduction in any medium, provided the original work is properly cited. 